\title{
Outside of the Classroom: How to Show a Great Film at Mason!
}

Laura Jenemann, University Libraries, and Mika'il Petin, African and African American Studies

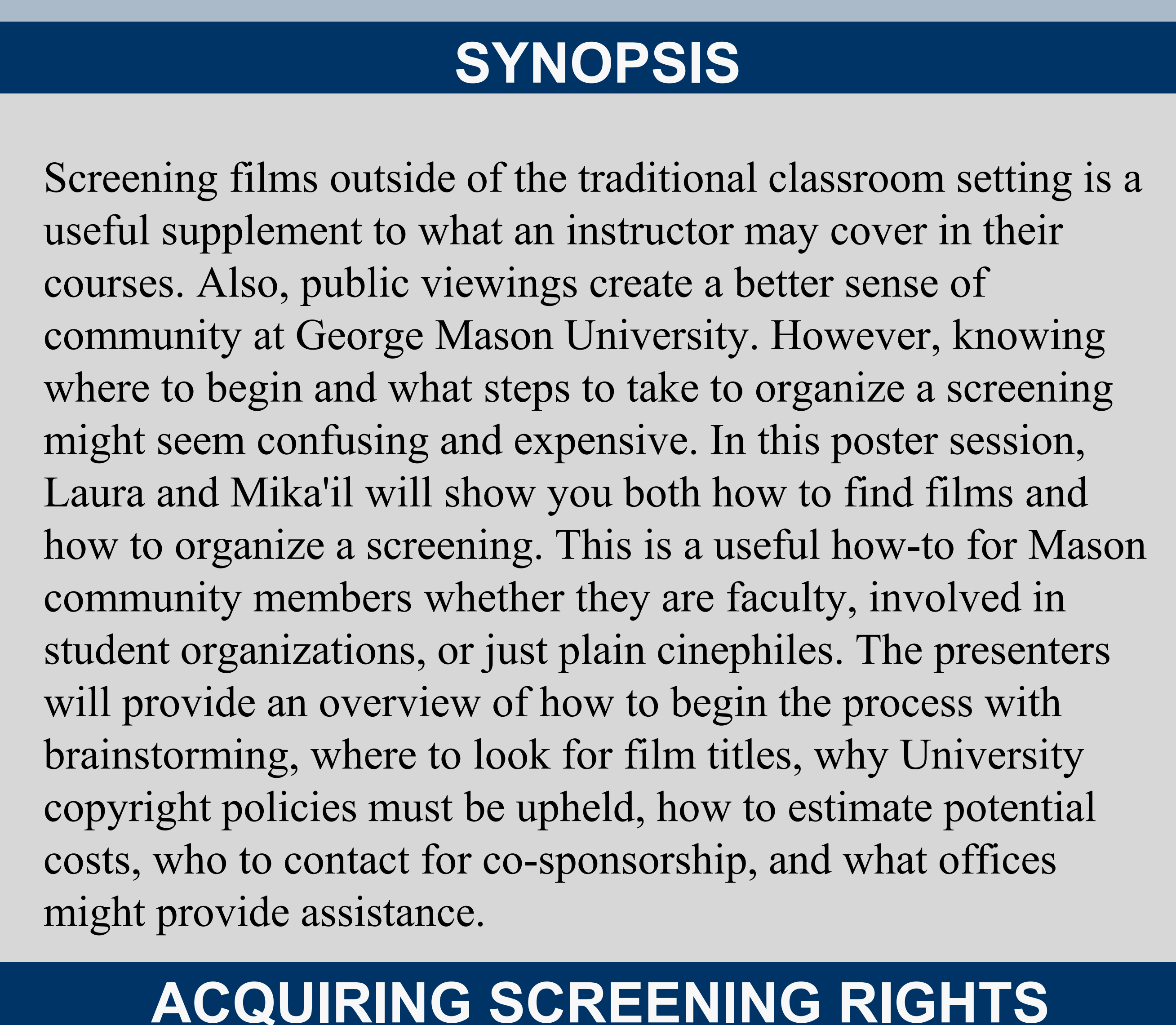

ACQUIRING SCREENING RIGHTS

If you want to screen a film outside of any Mason classroom, you will need to make sure that you (e.g. Mason faculty, staff, student) have the right to publicly display the film, commonly called "Public Performance Rights" (PPR). Often that right is an additional fee that can be $\$ 200$ or more.

Showing a film "publicly" is defined in Section 110(1) of the Copyright Law as showing a film outside an ordinary gathering of friends and family. If you open up a free screening to the general public, or run a student film club, your event is classified as a public event.

\section{THE CLASSROOM EXEMPTION}

Why don't you need to purchase PPR when you screen a film within the context of your class? Because most of Mason's classes fall under this exemption:

performance or display of a work by instructors or pupils in the course of face-to-face teaching activities of a nonprofit educational institution, in a classroom or similar place devoted to instruction...(17 U.S.C. \& 110.)

\section{WHY YOU SHOULD HOST A SCREENING}

- We currently live in an advanced society that is a visual culture.

- Today's students need to develop critical media literacy in order to interpret all the messages around them. The new forms of knowledge they are exposed to significantly influence what they comprehend during their encounters with education (Freedman, 2003).

- Film screenings can act as learning prompts that ask students to reflect on the applicability of the theories discussed during class time (Barkley, 2010).

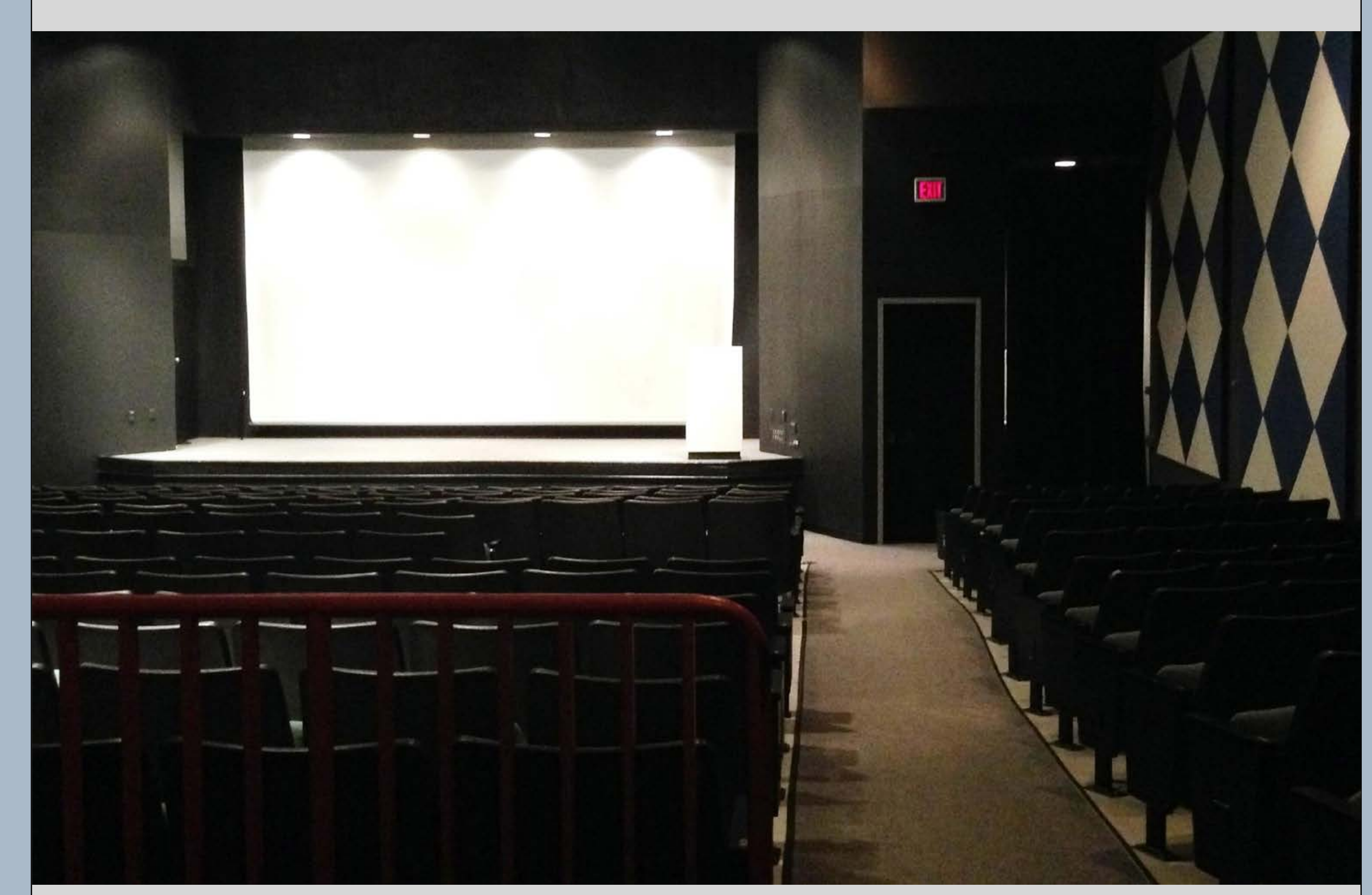

FINDING FILMS IN THE LIBRARY CATALOG

Did you know that you have *free* access to over a Did you know that you have "free" access to over a
thousand films with public performance rights (PPR) at the University Libraries?

Search for a film in the catalog and look for this note:

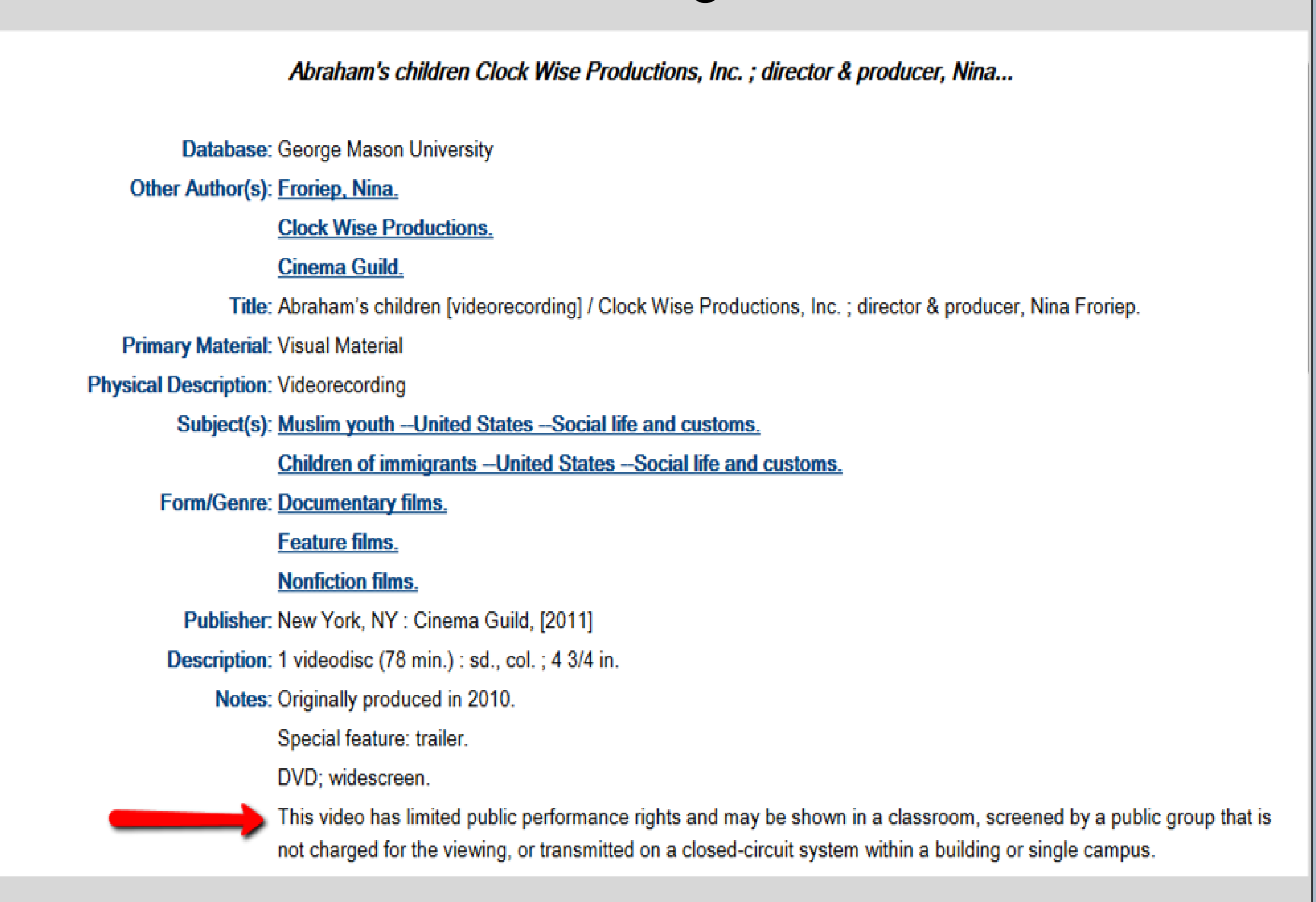

Don't see a note? Mason Libraries may still have PPR. Just contact Laura or your subject librarian.

\section{FUNDING YOUR SCREENING}

Here are just a few sources you can try:

- University Libraries, for finding films

- External grants

- Internal grants, e.g., University Life Programming

Committee and Auxiliary Enterprise Management Council

- Partnering with other offices, departments, and units, e.g. Office of Student Involvement and Global Interdisciplinary Programs

\section{PROMOTING YOUR SCREENING}

- Mason E-Files Announcements

- Today@Mason Calendar

- Flyers

- Social media

- Create an ad for TV screens across campus

- Ask other academic units or university groups to

- Ask other

- Offer extra credit to your students

\section{FINDING A VENUE}

- JC Cinema

Think about how many people you are expecting. For example, if you want to have breakout conversations after a screening, then consider a classroom.

- Check the University's scheduling website, 25Live, for room availability:

- $\frac{\text { http://scheduling.gmu.edu/25live/ }}{\text { Contact the Office of Events Management at }}$ gmuevent@gmu.edu for help or advice.

\section{ASSISTANCE AT SCREENING}

If you need technical assistance, request the assistance of a technician through Events Production, http://ep.gmu.edu/. Charges may apply.

\section{NOT ON THE FAIRFAX CAMPUS?}

Not on the Fairfax campus, but still need help?

- Contact Laura for help.

- Contact your subject librarian to request DVDs or Blu-ray discs.

- Also, DVDs can be shipped to you through intercampus loan.

\section{PLANNING YOUR SCREENING}

One of the best ways to have a successful screening is to make it relevant to a particular class, or use your screening as a tie-in to other events on campus.

Once you have an idea about a screening, start reaching out to related classes, events, and colleagues. Having a partner right from the start will help you create a screening event that will benefit more campus groups, increase attendance, and possibly lower costs.

Film screenings can be organized for *free*

You will want to plan and budget for the following:

- The cost of the film

- How will you project the film? DVD, Blu-ray, streaming? If you are using Events Production, there may be a charge.

- A guest speaker, if you are including one

- Promoting the event

- Refreshments

\section{CONTACT US}

Want to get started planning a screening? Contact Laura Jenemann, Media Services, Film Studies and Dance Librarian

ljeneman@gmu.edu

Want to hear about the experiences of another Mason community member? Contact Mika'il A. Petin, Associate Director, African and African American Studies

mpetin@gmu.edu

\section{REFERENCES}

Barkley, E. F. (2010). Student Engagement Techniques: A Handbook for College Faculty. San Francisco: Jossey-Bass.

Bruff, D. (2012). Flexible Space. Retrieved from http://www.flickr.com/photos/derekbruff/8045728599/

Copyright Law: Chapter 1: Limitations on exclusive rights: Exemption of certain performances and displays, 17 U.S.C. $\S$ 110. Retrieved from

http://www.copyright.gov/title17/92chap1.html\#110

Freedman, K. (2003). Teaching Visual Culture: Curriculum, Aesthetics, and the Social Life of Art. New York: Teachers
College Press; National Art Education Association. 